\title{
Article \\ Impact of the COVID-19 Pandemic on Healthcare-Seeking Behaviors among Frequent Emergency Department Users: A Cohort Study
}

\author{
Yi-Chang Chou $1,2,+\left(\mathbb{D}\right.$, Yung-Feng Yen ${ }^{1,2,3,4,5,+}$, Dachen Chu $6,7,8$ and Hsiao-Yun Hu $1,2,6, *$ (D) \\ 1 Department of Education and Research, Taipei City Hospital, Taipei 106, Taiwan; \\ T0036@tpech.gov.tw (Y.-C.C.); DAM37@tpech.gov.tw (Y.-F.Y.) \\ 2 Institute of Public Health, National Yang Ming Chiao Tung University, Taipei 112, Taiwan \\ 3 Section of Infectious Diseases, Taipei City Hospital, Yangming Branch, Taipei 111, Taiwan \\ 4 Department of Health Care Management, National Taipei University of Nursing and Health Sciences, \\ Taipei 112, Taiwan \\ 5 Department of Psychology and Counseling, University of Taipei, Taipei 100, Taiwan \\ 6 Department of Health and Welfare, University of Taipei, Taipei 100, Taiwan; dad57@tpech.gov.tw \\ 7 Institute of Hospital and Health Care Administration, National Yang Ming Chiao Tung University, \\ Taipei 112, Taiwan \\ 8 Department of Neurosurgery, Taipei City Hospital, Taipei 103, Taiwan \\ * Correspondence: A3547@tpech.gov.tw \\ $\dagger$ Contributed equally to this work.
}

Citation: Chou, Y.-C.; Yen, Y.-F.; Chu, D.; Hu, H.-Y. Impact of the COVID-19 Pandemic on Healthcare-Seeking Behaviors among Frequent Emergency Department Users: A Cohort Study. Int. J. Environ. Res. Public Health 2021, 18, 6351. https://doi.org/10.3390/ ijerph18126351

Received: 4 May 2021

Accepted: 8 June 2021

Published: 11 June 2021

Publisher's Note: MDPI stays neutral with regard to jurisdictional claims in published maps and institutional affiliations.

Copyright: (c) 2021 by the authors. Licensee MDPI, Basel, Switzerland. This article is an open access article distributed under the terms and conditions of the Creative Commons Attribution (CC BY) license (https:// creativecommons.org/licenses/by/ $4.0 /)$

\begin{abstract}
In 2020, Taiwan's healthcare system faced a notable burden imposed by the coronavirus disease (COVID-19) pandemic. Emergency department (ED) is a high-risk area for severe acute respiratory syndrome coronavirus 2 transmission. The effect of COVID-19 on the utilization of ED services among frequent ED users remains unknown. This cohort study determined the impact of the COVID-19 pandemic on healthcare-seeking behaviors among frequent ED users at Taipei City Hospital, Taiwan. We included ED users aged $\geq 18$ years admitted to Taipei City Hospital during February 2019-January 2020 (before the pandemic) and February 2020-January 2021 (during the pandemic). Frequent ED users were patients with four or more ED visits per year. Stepwise logistic regression was performed to identify predictors of frequent ED use during the COVID-19 pandemic. Frequent ED users had shorter hospital stays in the ED during the pandemic. After adjusting for sociodemographic factors and other covariates, patients with a triage status of level 4-5, pneumonia diagnosis, giddiness, or dyspnea were more likely frequent ED visitors during the COVID-19 pandemic. To reduce the risk of acquiring COVID-19, it is important to utilize territorial healthcare or telehealth to avoid inappropriate ED visits for patients with a low level of risk or chronic disease.
\end{abstract}

Keywords: emergency department; frequent users; COVID-19 pandemic

\section{Introduction}

Emergency department (ED) crowding is a burden on public health [1,2], so understanding the characteristics of frequent ED users is a key concern of healthcare systems and policy makers [3,4]. Taiwan's implementation of National Health Insurance in 1994 enhanced public access to healthcare. From 2000 to 2015, the number of ED visits in Taiwan increased by about $20.7 \%$, leading to ED crowding and a larger number of frequent ED users $[5,6]$.

As compared to occasional ED users, frequent ED users are older [7], have more chronic diseases [8], complex mental health problems [9,10], or drug addiction [11-13]. It has been shown that it is possible to reduce the number of visits by frequent ED users through certain intervention measures, such as case management, personal nursing care 
planning, strategies for pre-hospital transfer to non-emergency care, and enhanced primary care $[14,15]$. Therefore, identifying the features of frequent ED users and designing appropriate intervention measures are crucial tasks for reducing the frequency of ED visits and improving the relevant healthcare outcomes.

In 2020, Taiwan's healthcare system faced the significant challenge posed by the coronavirus disease (COVID-19) pandemic, and emergency care became the front-line tactic in the battle against this disease. To reduce disease transmission, the US Centers for Disease Control and Prevention (CDC) issued stay-at-home recommendations and encouraged local governments or healthcare systems to adopt corresponding policies or healthcare regulations.

The infectious nature of COVID-19 can influence patients to avoid visiting the hospital due to fears surrounding the rapid transmissibility of the disease. This restriction subsequently prevents patients from seeking medical care, which may decrease the utilization of ED services. A recent study conducted in the US showed that there was a $49.3 \%$ decline in ED visits after the declaration of the COVID-19 pandemic [16]. Another study conducted in Germany demonstrated a drop of $63.8 \%$ in pediatric emergency healthcare utilization during the COVID-19 pandemic [17]. Although recent studies have indicated a negative impact of the COVID-19 pandemic on the utilization of ED services, there has been scarce evidence for the impact of the COVID-19 pandemic on the utilization of ED services among frequent ED users.

The present study aimed to determine the impact of the COVID-19 pandemic on healthcare-seeking behaviors among frequent ED users at Taipei City Hospital (TCH), Taiwan. In addition, this study identified predictors associated with frequent ED use before and during the COVID-19 pandemic.

\section{Materials and Methods}

\subsection{Study Design and Setting}

$\mathrm{TCH}$, a 4700-bed hospital, is the largest healthcare organization in northern Taiwan. This cohort study examined patients who visited TCH Renai, Heping, and Zhongxiao branches in February 2019-January 2021. All information that could identify a specific individual patient was encrypted. After data encryption, emergency department data, medical utilization, discharge data, and demographic information was collected. The data used in the study were de-identified before the analysis took place. The study protocol was approved by the institutional review board (TCHIRB-10904009-E).

\subsection{Selection of Participants}

This cohort study compared the utilization of emergency medical services before (February 2019-January 2020) and during (February 2020-January 2021) the COVID-19 pandemic. Individuals aged $\geq 18$ years who visited the TCH ED during these two periods were included as participants. As this study intended to determine the impact of the COVID-19 pandemic on healthcare-seeking behaviors among adult frequent ED users, this study excluded the following types of patients from the analysis: pediatric ED users $(n=20,354)$, pregnant individuals $(n=809)$, and patients with out-of-hospital cardiac arrest deaths or death after an ED visit $(n=525)$ (Figure 1).

\subsection{Measurements}

Covariates identified as predictors [18] of frequent visit to the ED in previous studies were assessed in our analyses; these included the individuals' sociodemographic characteristics (sex, age, and copayment exemptions), triage status, mode of patient arrival, and most frequent primary diagnoses during ED visits. All medical records in the periods before and during the COVID-19 pandemic were collected. Subjects were classified into age groups of 18-34 years, 35-49 years, 50-64 years, 65-79 years, and $\geq 80$ years. Most patients with copayment exemptions had catastrophic illnesses and were exempt from paying approximately US $\$ 10$ in medical expenses [19]. The characteristics of ED visit 
included the time of ED visit (8 a.m.-4 p.m., 4 p.m.- 0 a.m., 0 a.m.- 8 a.m.), disposition of ED visit (discharge, hospitalization), triage status of patient severity (levels 1-5) [20], mode of patient arrival (walk-in, referral from other institutions, ambulance), average length of stay (LOS) in the ED, average medical expenses, cancer, chest radiography, and chest computed tomography $(\mathrm{CT})$ examination. Data of the ten most frequent primary diagnoses in ED visits were also collected for the periods before and during the COVID-19 pandemic.

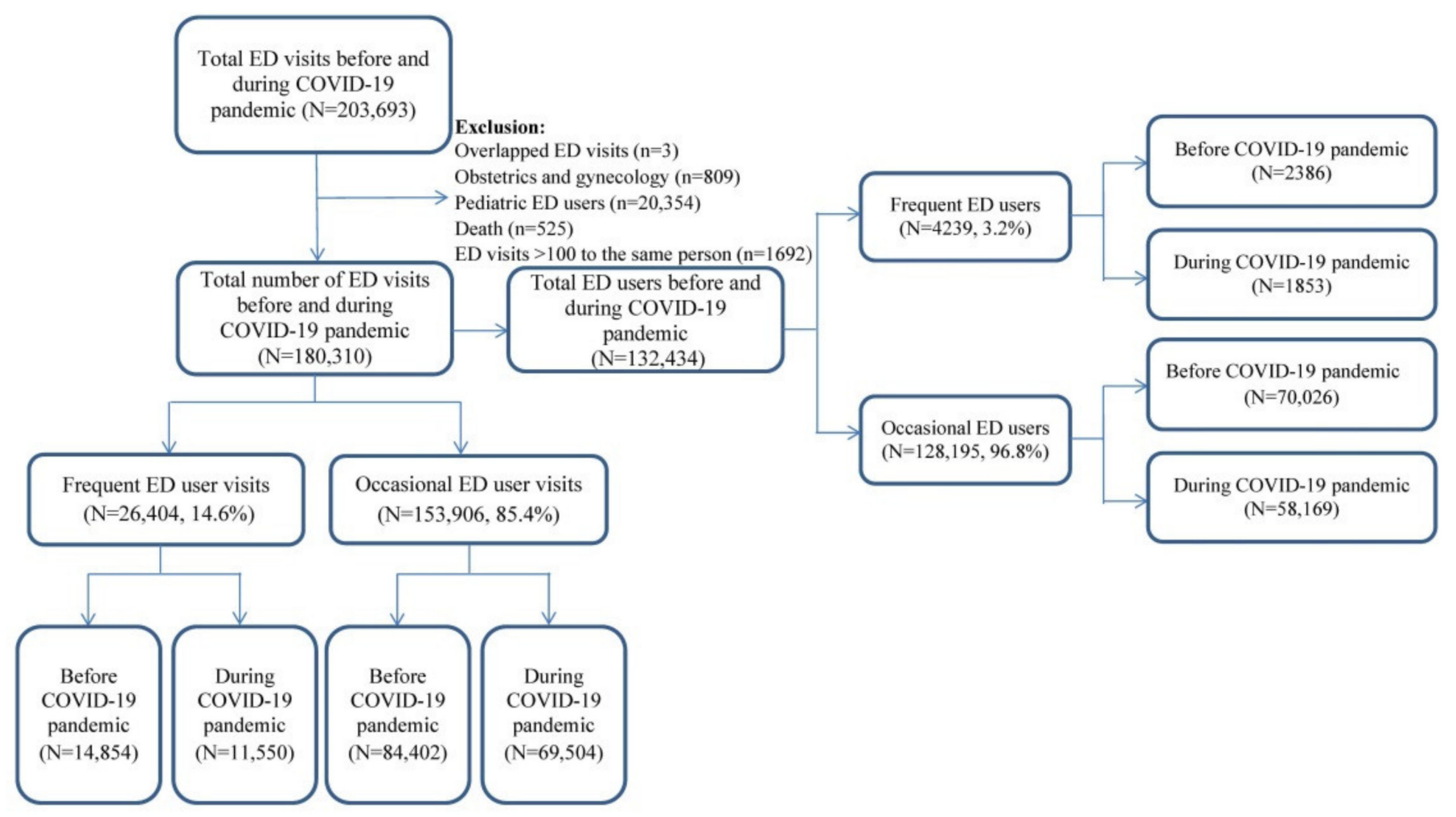

Figure 1. Flow chart of the patient selection process.

\subsection{Outcomes}

The outcome variable was the frequency of ED user visits before and during the COVID-19 pandemic. Frequent ED users were defined as those with four or more ED visits in a year, and occasional ED users were defined as those with one to three ED visits $[2,10,21]$.

\subsection{Data Analysis}

Analyses were performed on the personal characteristics, healthcare utilization characteristics, and the top ten primary diagnoses before and during the COVID-19 pandemic for frequent and occasional ED users. The data were presented as percentages, and a chi-squared test or Student's $t$-test was performed to compare the differences between the periods before and during the pandemic. The predictors for frequent ED use were analyzed using multivariate logistic regression, and the forward stepwise regression model was adopted, adjusting for age, sex, triage status, mode of patient arrival, copayment exemption status, and top ten primary diagnoses of the given year. Statistical significance was set at 5\%, and all analyses were conducted using SAS (version 9.4; SAS Institute, Inc., Cary, NC, USA). 


\section{Results \\ 3.1. Characteristics of Study Subjects}

In total, 132,434 patients who visited the TCH ED before and during the pandemic were included in this study. The number of ED users significantly decreased from 72,412 before the COVID-19 pandemic to 60,022 during the COVID-19 pandemic $(p=0.032)$. The overall mean (standard deviation) age was 49.6 (21.0) years, and $49.2 \%$ of the participants were male. Of the 132,434 patients, $12,423(9.4 \%)$ had medical records for both periods. Frequent ED users accounted for 3.3\% (2386 cases) and 3.1\% (1853 cases) of ED patients before and during the COVID-19 pandemic, respectively (Table 1).

Table 1. Characteristics of ED patients before (February 2019-January 2020) and during COVID-19 pandemic (February 2020January 2021) $(n=132,434)$.

\begin{tabular}{|c|c|c|c|c|c|c|}
\hline \multirow[b]{2}{*}{ n (\%) } & \multicolumn{2}{|c|}{ Frequent ED Users } & \multirow{2}{*}{$p$-Value } & \multicolumn{2}{|c|}{ Occasional ED Users } & \multirow{2}{*}{$p$-Value } \\
\hline & Before & During & & Before & During & \\
\hline $\begin{array}{l}\text { Total } \\
\text { Sex }\end{array}$ & $2386(3.3)$ & $1853(3.1)$ & & $70,026(96.7)$ & $58,169(96.9)$ & 0.032 \\
\hline Male & $1276(53.5)$ & $1016(54.8)$ & 0.381 & $33,932(48.5)$ & $28,938(49.8)$ & $<0.0001$ \\
\hline Female & $1110(46.5)$ & $837(45.2)$ & & $36,094(51.5)$ & $29,231(50.2)$ & \\
\hline Age, y (Mean \pm SD) & $65.3 \pm 20.7$ & $65.0 \pm 20.7$ & 0.605 & $50.0 \pm 21.0$ & $49.9 \pm 21.3$ & 0.347 \\
\hline $18-34$ & $249(10.4)$ & $199(10.7)$ & 0.247 & $20,979(30.0)$ & $18,233(31.3)$ & $<0.0001$ \\
\hline $35-49$ & 325 (13.6) & $252(13.6)$ & & $14,836(21.2)$ & $11,877(20.4)$ & \\
\hline $50-64$ & $487(20.4)$ & $365(19.7)$ & & $14,818(21.2)$ & $11,631(20.0)$ & \\
\hline $65-79$ & $556(23.3)$ & $483(26.1)$ & & $11,906(17.0)$ & $9788(16.8)$ & \\
\hline$>80$ & $769(32.2)$ & $554(29.9)$ & & 7487 (10.7) & $6640(11.4)$ & \\
\hline \multicolumn{7}{|c|}{ Copayment exemptions } \\
\hline Yes & $852(35.7)$ & $696(37.6)$ & 0.214 & 7977 (11.4) & $7000(12.0)$ & $<0.0001$ \\
\hline No & $1534(64.3)$ & 1157 (62.4) & & $62,049(88.6)$ & $51,169(88.0)$ & \\
\hline
\end{tabular}

ED, Emergency Department.

\subsection{Trend of Monthly Emergency Department Visits before and during COVID-19 Pandemic}

Figure 2 shows the trend of monthly ED visits before and during the COVID-19 pandemic. After the start of the COVID-19 outbreak in January 2020, the number of ED visits during the COVID-19 pandemic significantly decreased by $10.1-26.8 \%$ compared to that before the COVID-19 pandemic $(p<0.0001)$. During the COVID-19 pandemic, the number of laboratory-confirmed COVID-19 cases in Taiwan significantly decreased from 283 cases in March to 20 cases in July. The number of monthly ED visits during the COVID-19 pandemic slightly increased from 6202 ED visits in March to 7196 ED visits in July $(p=0.004)$, which, however, was lower than before the COVID-19 pandemic.

\subsection{Characteristics of ED Visits before and during COVID-19 Pandemic}

A total of 180,310 ED visits were recorded during the study period, including 99,256 (55.1\%) and $81,054(44.9 \%)$ before and during the COVID-19 pandemic, respectively. In terms of frequent ED users, that is those visiting the ED four times or more, these patients had a shorter length of stay in the ED compared to before the COVID-19 pandemic (212.5 vs. 233.9 min; $p<0.0001$ ) (Table 2). 


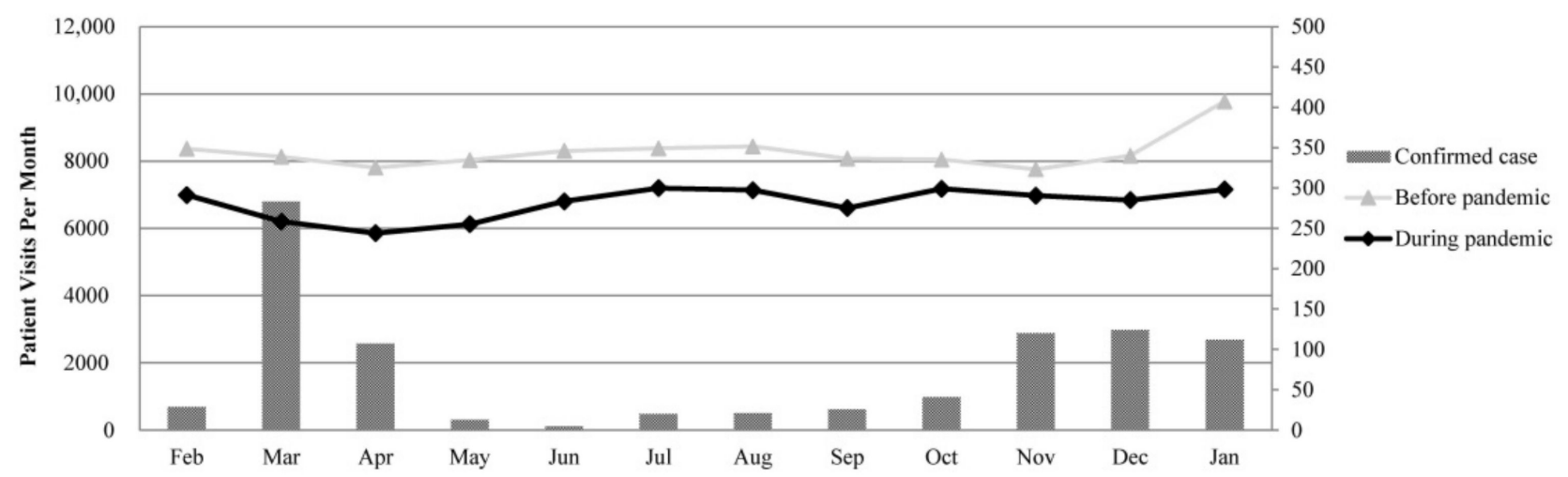

Figure 2. Trend of monthly emergency department visits before and during the COVID-19 pandemic.

Table 2. Characteristics of ED visits before (February 2019-January 2020) and during the COVID-19 pandemic (February 2020 -January 2021) $(n=180,310)$.

\begin{tabular}{|c|c|c|c|c|c|c|}
\hline \multirow[b]{2}{*}{$N(\%)$} & \multicolumn{2}{|c|}{ Frequent ED Users } & \multirow{2}{*}{$p$-Value } & \multicolumn{2}{|c|}{ Occasional ED Users } & \multirow{2}{*}{$p$-Value } \\
\hline & Before & During & & Before & During & \\
\hline Total & $14,854(15.0)$ & $11,550(14.2)$ & & $84,402(85.0)$ & $69,504(85.8)$ & \\
\hline \multicolumn{7}{|l|}{ Time of visits } \\
\hline Daytime (8 a.m. -4 p.m.) & $6534(44.0)$ & $5129(44.4)$ & 0.737 & $34,611(41.0)$ & $28,858(41.5)$ & 0.010 \\
\hline Evening (4 p.m.-0 a.m.) & $5674(38.2)$ & $4398(38.1)$ & & $35,868(42.5)$ & $29,366(42.3)$ & \\
\hline Early morning ( 0 a.m. -8 a.m.) & $2646(17.8)$ & $2023(17.5)$ & & $13,923(16.5)$ & $11,280(16.2)$ & \\
\hline \multicolumn{7}{|l|}{ Disposition } \\
\hline Discharged & $11,983(80.7)$ & $9246(80.1)$ & 0.208 & $72,265(85.6)$ & $58,763(84.5)$ & $<0.0001$ \\
\hline Hospitalization & $2871(19.3)$ & $2304(19.9)$ & & $12,137(14.4)$ & $10,741(15.5)$ & \\
\hline \multicolumn{7}{|l|}{ Triage status } \\
\hline 1 (high) & $379(2.5)$ & $309(2.7)$ & 0.006 & $1516(1.8)$ & $1472(2.1)$ & $<0.0001$ \\
\hline 2 & $1590(10.7)$ & $1247(10.8)$ & & $6760(8.0)$ & $5401(7.8)$ & \\
\hline 3 & $8034(54.1)$ & $6468(56.0)$ & & $53,529(63.4)$ & $44,505(64.0)$ & \\
\hline 4 & $3945(26.6)$ & $2882(24.9)$ & & $20,551(24.4)$ & $15,559(22.4)$ & \\
\hline 5 (low) & $906(6.1)$ & $644(5.6)$ & & $2046(2.4)$ & $2567(3.7)$ & \\
\hline \multicolumn{7}{|l|}{ Mode of arrival } \\
\hline Ambulatory & $10,734(72.3)$ & $8712(75.5)$ & $<0.0001$ & $61,118(72.4)$ & $51,932(74.8)$ & $<0.0001$ \\
\hline EMS & $2560(17.2)$ & $2268(19.7)$ & & $15,397(18.2)$ & $14,127(20.3)$ & \\
\hline Referral & $1560(10.5)$ & $552(4.8)$ & & $7887(9.3)$ & $3381(4.9)$ & \\
\hline Cancer & & & 0.150 & & & 0.300 \\
\hline No & $2232(93.6)$ & $1753(94.6)$ & & $69,412(99.1)$ & $57,627(99.1)$ & \\
\hline Yes & $154(6.4)$ & $100(5.4)$ & & $614(0.9)$ & $542(0.9)$ & \\
\hline Over $24-\mathrm{h}$ LOS & $2259(15.2)$ & $1831(15.9)$ & 0.151 & $12,908(15.3)$ & $11,156(16.1)$ & $<0.0001$ \\
\hline Length of stay (minutes) (Mean \pm SD) & $233.9 \pm 366.1$ & $212.5 \pm 320.5$ & $<0.0001$ & $156.7 \pm 268.3$ & $154.4 \pm 239.7$ & 0.068 \\
\hline Medical expenses* (USD) (Mean \pm SD) & $108.4 \pm 109.7$ & $117.6 \pm 111.0$ & $<0.0001$ & $102.1 \pm 115.9$ & $113.8 \pm 110.0$ & $<0.0001$ \\
\hline Chest X-ray & $5768(38.8)$ & $4628(40.1)$ & 0.041 & $28,332(33.6)$ & $26,670(38.4)$ & $<0.0001$ \\
\hline Chest CT examination & $72(0.5)$ & $120(1.0)$ & $<0.0001$ & $513(0.6)$ & $806(1.2)$ & $<0.0001$ \\
\hline
\end{tabular}

ED, emergency department; EMS, emergency medical services; LOS, length of stay. * Medical expenses are presented in US dollars. (US dollars: NT dollars = 1:28.14). 12 March 2021.

\subsection{Primary Diagnoses in ED Users before and during COVID-19 Pandemic}

The top ten most frequent primary diagnoses in ED users were analyzed before and during the COVID-19 pandemic (Appendix A, Table A1). Among frequent ED users, the most frequent primary diagnoses during the COVID-19 pandemic were dizziness and giddiness $(5.71 \%)$, followed by abdominal and pelvic pain $(5.68 \%)$, and fever of unknown origin (3.55\%). Moreover, the top three primary diagnoses among frequent ED users before the COVID-19 pandemic were abdominal and pelvic pain (5.75\%), dizziness and giddiness $(5.04 \%)$, and fever of unknown origin $(4.10 \%)$. 


\subsection{Factors Associated with Frequent ED Users before and during COVID-19 Pandemic}

Table 3 shows the multivariate analyses for factors associated with frequent ED users before and during the COVID-19 pandemic. After adjusting for sociodemographic factors and other covariates, patients with a triage status of level $4-5$ (AOR $=1.63,95 \%$ CI: $1.15-2.31$, a diagnosis of pneumonia ( $\mathrm{AOR}=1.88,95 \% \mathrm{CI}: 1.09-3.24)$, dizziness and giddiness $(\mathrm{AOR}=2.88,95 \% \mathrm{CI}: 1.84-4.52)$, dyspnea (AOR $=1.83,95 \% \mathrm{CI}: 0.99-3.37)$, or chronic kidney disease ( $\mathrm{AOR}=5.07,95 \% \mathrm{CI}$ : 2.66-9.69) were more likely to visit the ED four or more times during the COVID-19 pandemic. Moreover, patients aged $\geq 65$ years, those with copayment exemptions, and those with cancer were more likely to visit the ED four or more times before and during the COVID-19 pandemic.

Table 3. Factors associated with frequent ED users before (February 2019-January 2020) and during the COVID-19 pandemic (February 2020-January 2021).

\begin{tabular}{|c|c|c|c|c|c|}
\hline \multicolumn{3}{|c|}{ Before the COVID-19 Pandemic } & \multicolumn{3}{|c|}{ During the COVID-19 Pandemic } \\
\hline Independent Variables & $\begin{array}{l}\text { Adjusted OR } \\
\quad(95 \% \mathrm{CI})\end{array}$ & $p$-Value & Independent Variables & $\begin{array}{l}\text { Adjusted OR } \\
\quad(95 \% \mathrm{CI})\end{array}$ & $p$-Value \\
\hline Age $\geq 65$ & $2.94(2.48-3.48)$ & $<0.0001$ & Age $\geq 65$ & $2.89(2.38-3.50)$ & $<0.0001$ \\
\hline $\begin{array}{l}\text { Time of visits, evening } \\
(1600-2400)\end{array}$ & $0.80(0.68-0.95)$ & 0.009 & $\begin{array}{l}\text { Time of visits, early morning } \\
(0000-0800)\end{array}$ & $1.38(1.08-1.77)$ & 0.011 \\
\hline Mode of arrival, EMS & $0.56(0.43-0.72)$ & $<0.0001$ & Mode of arrival, EMS & $0.73(0.56-0.95)$ & 0.019 \\
\hline Copayment exemptions & $3.94(3.31-4.68)$ & $<0.0001$ & Copayment exemptions & $3.76(3.10-4.56)$ & $<0.0001$ \\
\hline Primary diagnosis in the ED & & & Triage status, $4-5$ & $1.63(1.15-2.31)$ & 0.006 \\
\hline Other anemias & $4.55(2.54-8.16)$ & $<0.0001$ & Primary diagnosis in the ED & & \\
\hline Retention of urine & $3.26(1.69-6.28)$ & $<0.0001$ & Dizziness and giddiness & $2.88(1.84-4.52)$ & $<0.0001$ \\
\hline Pain in throat and chest & $1.88(1.13-3.12)$ & 0.015 & Other anemias & $5.14(3.16-8.37)$ & $<0.0001$ \\
\hline Dizziness and giddiness & $1.67(1.01-2.77)$ & 0.047 & Dyspnea & $1.83(0.99-3.37)$ & 0.053 \\
\hline \multirow[t]{4}{*}{ Comorbidity of cancer } & $5.69(3.81-8.50)$ & $<0.0001$ & Retention of urine & $5.56(3.05-10.1)$ & $<0.0001$ \\
\hline & & & $\begin{array}{c}\text { Pneumonia, unspecified } \\
\text { organism }\end{array}$ & $1.88(1.09-3.24)$ & 0.023 \\
\hline & & & Chronic kidney disease & $5.07(2.66-9.69)$ & $<0.0001$ \\
\hline & & & Comorbidity of cancer & $3.41(2.05-5.58)$ & $<0.0001$ \\
\hline
\end{tabular}

ED, emergency department; CI, confidence interval; OR, odds ratio. Adjusted for age, sex, time of visits, triage status, mode of arrival, copayment exemptions, and the most frequent primary diagnoses among ED users before and during the COVID-19 pandemic.

\section{Discussion}

This study found that the utilization of emergency medical services during the COVID19 pandemic significantly decreased by $10.1-26.8 \%$ compared to before the COVID-19 pandemic. The LOS in frequent ED users during the COVID-19 pandemic was significantly shorter than that before the COVID-19 pandemic. Furthermore, patients with a triage status of level $4-5$, or a diagnosis of pneumonia, giddiness, or dyspnea were more likely to frequently utilize the emergency medical services during the COVID-19 pandemic.

This cohort study showed that the overall ED service volume during the COVID-19 pandemic in Taiwan decreased significantly by $26.8 \%$, which was lower than the reductions of 39.6\% seen in EDs in the US [22] and 63.8\% in the pediatric ED in Germany [17]. The relatively lower impact of the COVID-19 pandemic on the utilization of ED services in Taiwan may be due to the successful control of the COVID-19 pandemic in 2020. As the COVID-19 outbreak emerged, the Taiwanese government implemented several strategies to prevent the nationwide spread of COVID-19, including border controls, proactive screening measures, and quarantine procedures [23,24]. By 31 January 2021, 911 laboratory-confirmed COVID-19 cases were reported to the Taiwan Centers for Disease Control and Prevention (CDC), including 797 (87.5\%) imported cases [25]. Although Taiwan successfully controlled the spread of the COVID-19 pandemic in the country in 2020, there was still a significant overall reduction in ED utilization. As ED services provide treatments for patients with acute illnesses, it is important to raise patient awareness regarding acute health conditions 
that are deadlier than COVID-19 and that require immediate medical intervention to ensure health and recovery.

With regards to the utilization of ED services, the average LOS of frequent ED users showed a significant decrease of $21.4 \mathrm{~min}(p<0.0001)$. This could be attributed to the COVID-19 pandemic, with physicians reducing observation times in order to avoid the risk of nosocomial infections. A previous study in Canada showed that the length of stay in ED users was significantly decreased in a pediatric emergency department during the SARS pandemic of 2003 [26]. Patients staying in the ED for longer periods of time during the COVID-19 pandemic increases the risk of a SARS-CoV-2 outbreak in crowded ED departments. The findings of our study suggest that it is important to reduce the LOS of ED users to prevent the occurrence of SARS-CoV-2 infection in these patients.

This study found that patients with a diagnosis of pneumonia were more likely to utilize emergency medical services frequently during the COVID-19 pandemic. The implementation of enhanced traffic control bundling (eTCB) to prevent COVID-19 outbreaks in Taiwan may explain the high frequency of emergency medical service use in patients with a diagnosis of pneumonia. In the beginning of the COVID-19 epidemic in 2020, Taiwan CDC implemented eTCB in nationwide hospitals to secure the healthcare system [27]. At the hospital entrance, all patients were required to undergo body temperature and TOCC (i.e., travel history, occupation, contact history, and clusters) checks before entering. If patients at the hospital entrance presented with fever, symptoms of pneumonia, or a history of visiting regions with a declared COVID-19 outbreak during the last 14 days, they were referred to the ED for a COVID-19 examination. Since healthcare workers are vulnerable to SARS-CoV-2 infection, the urgent adoption of strict COVID-19 prevention strategies was essential to prevent COVID-19 outbreaks in healthcare settings.

This study showed that patients with triage status of level $4-5$ or the symptoms of dizziness or giddiness were more likely to frequently utilize ED medical services during the COVID-19 pandemic. The increasing burden of COVID-19-related psychological disorders may explain the high frequency of the utilization of emergency medical services in patients with a triage status of level $4-5$ or the symptoms of dizziness or giddiness. Recent reports have shown that the COVID-19 pandemic has increased the burden of mental and psychological problems in the general public [28-30], which could increase the utilization of emergency medical services. Since SARS-CoV-2 is highly contagious, it is imperative to educate non-emergency patients to utilize outpatient medical services rather than emergency medical services to reduce the risk of COVID-19 infection and outbreaks at ED.

There were two limitations to this study. First, the data for ED visits originated from a single hospital, which did not include all ED visits in the entire region. However, due to the COVID-19 pandemic, people have reduced their use of public transport and opted for hospitals closer to their homes, in order to avoid the risk of infection, while also cutting down on unnecessary visits. Therefore, cases where patients visit different hospitals for the same disease were expected to have decreased. Second, although TCH is the largest healthcare organization in northern Taiwan, our subjects were selected only from a single hospital. Therefore, the external validity of our findings may be of concern, and the generalizability of our results to hospital settings other than non-Asian ethnic groups requires further verification.

\section{Conclusions}

This cohort study demonstrated that the utilization of emergency medical services was significantly decreased during the COVID-19 pandemic. Patients with a triage status of level 4-5, a pneumonia diagnosis, giddiness, or dyspnea were more likely to frequently utilize the emergency medical services during the COVID-19 pandemic. To reduce the risk of SARS-CoV-2 infection transmission, it is important to utilize territorial healthcare or telehealth to avoid inappropriate ED visits for patients with a low level of risk or with chronic disease. 
Author Contributions: Conceptualization, Y.-C.C., Y.-F.Y. and H.-Y.H.; methodology, Y.-C.C., Y.-F.Y., D.C. and H.-Y.H.; formal analysis, Y.-C.C. and H.-Y.H.; writing-original draft preparation, Y.-C.C. and Y.-F.Y.; writing-review and editing, Y.-C.C., Y.-F.Y., D.C. and H.-Y.H.; funding acquisition, H.-Y.H. All authors have read and agreed to the published version of the manuscript.

Funding: Funded by the Ministry of Science and Technology, Taiwan (MOST108-2635-B-532-001).

Institutional Review Board Statement: The study was conducted according to the Declaration of Helsinki guidelines and approved by the Institutional Review Board of Taipei City Hospital (TCHIRB-10904009-E).

Informed Consent Statement: This study was conducted by analyzing datasets, and the raw data were de-identified. Therefore, the Research Ethics Committee agreed to waive the informed consent due to minimal risk within the study.

Data Availability Statement: The datasets produced and analyzed during the present study are available from the corresponding author upon reasonable request.

Acknowledgments: We thank all the study participants and staff for their assistance.

Conflicts of Interest: The authors declare no conflict of interest.

\section{Appendix A}

Table A1. The ten most frequent primary diagnoses among frequent and occasional ED users before (February 2019-January 2020) and during the COVID-19 pandemic (February 2020-January 2021) $(n=180,310)$.

\begin{tabular}{|c|c|c|c|}
\hline \multicolumn{4}{|c|}{ Frequent ED Users $(n=26,404)$} \\
\hline Before the COVID-19 Pandemic ( $n=14,854)$ & $\mathbf{N}(\%)$ & During the COVID-19 Pandemic $(n=11,550)$ & $\mathbf{N}(\%)$ \\
\hline Abdominal and pelvic pain & 855 (5.75) & Dizziness and giddiness & $660(5.71)$ \\
\hline Dizziness and giddiness & $749(5.04)$ & Abdominal and pelvic pain & $657(5.68)$ \\
\hline Fever of other and unknown origin & $610(4.10)$ & Fever of other and unknown origin & $411(3.55)$ \\
\hline Other anemias & $461(3.10)$ & Other anemias & $400(3.46)$ \\
\hline Pneumonia, unspecified organism & $437(2.94)$ & Pain in throat and chest & $391(3.38)$ \\
\hline Retention of urine & $379(2.55)$ & Dsypnea & $330(2.85)$ \\
\hline Pain in throat and chest & $377(2.53)$ & Other disorders of urinary system & $312(2.70)$ \\
\hline Other disorders of urinary system & $354(2.38)$ & Retention of urine & $293(2.53)$ \\
\hline Dsypnea & $343(2.30)$ & Pneumonia, unspecified organism & $244(2.11)$ \\
\hline Other chronic obstructive pulmonary disease & $337(2.26)$ & Chronic kidney disease (CKD) & $227(1.96)$ \\
\hline \multicolumn{4}{|c|}{ Occasional ED Users $(n=153,906)$} \\
\hline Before the COVID-19 Pandemic $(n=84,402)$ & N (\%) & During the COVID-19 Pandemic $(n=69,504)$ & $\mathbf{N}(\%)$ \\
\hline Abdominal and pelvic pain & $5306(6.28)$ & Abdominal and pelvic pain & $4176(6.00)$ \\
\hline Fever of other and unknown origin & $4389(5.20)$ & Fever of other and unknown origin & $3054(4.39)$ \\
\hline Dizziness and giddiness & $3052(3.61)$ & Dizziness and giddiness & $2740(3.94)$ \\
\hline Open wound of wrist, hand, and fingers & $2655(3.14)$ & Open wound of wrist, hand, and fingers & $2402(3.45)$ \\
\hline Superficial injury of head & $2339(2.77)$ & Pain in throat and chest & $1911(2.74)$ \\
\hline $\begin{array}{l}\text { Other and unspecified noninfective } \\
\text { gastroenteritis and colitis }\end{array}$ & $2269(2.68)$ & Superficial injury of head & $1719(2.47)$ \\
\hline Other disorders of urinary system & $1906(2.25)$ & $\begin{array}{l}\text { Other and unspecified noninfective } \\
\text { gastroenteritis and colitis }\end{array}$ & $1631(2.34)$ \\
\hline Pain in throat and chest & $1798(2.13)$ & Other disorders of urinary system & $1573(2.26)$ \\
\hline Pneumonia, unspecified organism & $1746(2.06)$ & Superficial injury of knee and lower leg & $1542(2.21)$ \\
\hline Injury of unspecified body region & $1651(1.95)$ & Intracranial injury & $1395(2.00)$ \\
\hline
\end{tabular}




\section{References}

1. Pines, J.M.; Hilton, J.A.; Weber, E.J.; Alkemade, A.J.; Al Shabanah, H.; Anderson, P.D.; Bernhard, M.; Bertini, A.; Gries, A.; Ferrandiz, S.; et al. International perspectives on emergency department crowding. Acad. Emerg. Med. 2011, 18, 1358-1370. [CrossRef]

2. Lee, J.H.; Park, G.J.; Kim, S.C.; Kim, H.; Lee, S.W. Characteristics of frequent adult emergency department users: A Korean tertiary hospital observational study. Medicine 2020, 99, e20123. [CrossRef] [PubMed]

3. Shapiro, J.S.; Johnson, S.A.; Angiollilo, J.; Fleischman, W.; Onyile, A.; Kuperman, G. Health information exchange improves identification of frequent emergency department users. Health Aff. 2013, 32, 2193-2198. [CrossRef] [PubMed]

4. Fuda, K.K.; Immekus, R. Frequent users of Massachusetts emergency departments: A statewide analysis. Ann. Emerg. Med. 2006, 48, 9-16. [CrossRef]

5. $\quad$ Chang, Y.H.; Shih, H.M.; Chen, C.Y.; Chen, W.K.; Huang, F.W.; Muo, C.H. Association of sudden in-hospital cardiac arrest with emergency department crowding. Resuscitation 2019, 138, 106-109. [CrossRef]

6. Chen, C.H.; Hsieh, J.G.; Cheng, S.L.; Lin, Y.L.; Lin, P.H.; Jeng, J.H. Early short-term prediction of emergency department length of stay using natural language processing for low-acuity outpatients. Am. J. Emerg. Med. 2020, 38, 2368-2373. [CrossRef]

7. Afonso, S.; Lopes, S. Differences in Clinical Characteristics and Utilization of Emergency Department by High-Frequency Users. J. Emerg. Med. 2020, 59, 153-160. [CrossRef]

8. Moe, J.; Kirkland, S.; Ospina, M.B.; Campbell, S.; Long, R.; Davidson, A.; Duke, P.; Tamura, T.; Trahan, L.; Rowe, B.H. Mortality, admission rates and outpatient use among frequent users of emergency departments: A systematic review. Emerg. Med. J. 2016, 33, 230-236. [CrossRef]

9. Chan, B.T.; Ovens, H.J. Frequent users of emergency departments. Do they also use family physicians' services? Can. Fam Physician 2002, 48, 1654-1660.

10. Bieler, G.; Paroz, S.; Faouzi, M.; Trueb, L.; Vaucher, P.; Althaus, F.; Daeppen, J.B.; Bodenmann, P. Social and medical vulnerability factors of emergency department frequent users in a universal health insurance system. Acad. Emerg. Med. 2012, 19, 63-68. [CrossRef]

11. Mandelberg, J.H.; Kuhn, R.E.; Kohn, M.A. Epidemiologic analysis of an urban, public emergency department's frequent users. Acad. Emerg. Med. 2000, 7, 637-646. [CrossRef] [PubMed]

12. Huang, J.A.; Tsai, W.C.; Chen, Y.C.; Hu, W.H.; Yang, D.Y. Factors associated with frequent use of emergency services in a medical center. J. Med. Assoc. 2003, 102, 222-228.

13. Cherpitel, C.J.; Ye, Y. Drug use and problem drinking associated with primary care and emergency room utilization in the US general population: Data from the 2005 national alcohol survey. Drug Alcohol Depend. 2008, 97, 226-230. [CrossRef] [PubMed]

14. Van den Heede, K.; Van de Voorde, C. Interventions to reduce emergency department utilisation: A review of reviews. Health Policy 2016, 120, 1337-1349. [CrossRef] [PubMed]

15. Moe, J.; Kirkland, S.W.; Rawe, E.; Ospina, M.B.; Vandermeer, B.; Campbell, S.; Rowe, B.H. Effectiveness of interventions to decrease emergency department visits by adult frequent users: A systematic review. Acad. Emerg. Med. 2017, 24, 40-52. [CrossRef] [PubMed]

16. Westgard, B.C.; Morgan, M.W.; Vazquez-Benitez, G.; Erickson, L.O.; Zwank, M.D. An analysis of changes in emergency department visits after a state declaration during the time of COVID-19. Ann. Emerg. Med. 2020, 76, 595-601. [CrossRef] [PubMed]

17. Dopfer, C.; Wetzke, M.; Scharff, A.Z.; Mueller, F.; Dressler, F.; Baumann, U.; Sasse, M.; Hansen, G.; Jablonka, A.; Happle, C. COVID-19 related reduction in pediatric emergency healthcare utilization-a concerning trend. BMC Pediatrics 2020, 20, 1-10. [CrossRef]

18. Pines, J.M.; Asplin, B.R.; Kaji, A.H.; Lowe, R.A.; Magid, D.J.; Raven, M.; Weber, E.J.; Yealy, D.M. Frequent users of emergency department services: Gaps in knowledge and a proposed research agenda. Acad. Emerg. Med. 2011, 18, e64-e69. [CrossRef]

19. Copayments. Available online: https:/ / www.nhi.gov.tw/English/Content_List.aspx?n=E5509C8FE29950EA\&topn=1D1ECC5 4F86E9050 (accessed on 16 March 2021).

20. Ng, C.J.; Yen, Z.S.; Tsai, J.C.; Chen, L.C.; Lin, S.J.; Sang, Y.Y.; Chen, J.C.; TTAS National Working Group. Validation of the Taiwan triage and acuity scale: A new computerised five-level triage system. Emerg. Med. J. 2011, 28, 1026-1031. [CrossRef]

21. Hunt, K.A.; Weber, E.J.; Showstack, J.A.; Colby, D.C.; Callaham, M.L. Characteristics of frequent users of emergency departments. Ann. Emerg. Med. 2006, 48, 1-8. [CrossRef]

22. Lucero, A.D.; Lee, A.; Hyun, J.; Lee, C.; Kahwaji, C.; Miller, G.; Neeki, M.; Tamayo-Sarver, J.; Pan, L. Underutilization of the Emergency Department During the COVID-19 Pandemic. West. J. Emerg. Med. 2020, 21, 15. [CrossRef] [PubMed]

23. Wang, C.J.; Ng, C.Y.; Brook, R.H. Response to COVID-19 in Taiwan: Big data analytics, new technology, and proactive testing. JAMA 2020, 323, 1341-1342. [CrossRef] [PubMed]

24. Cheng, H.Y.; Li, S.Y.; Yang, C.H. Initial rapid and proactive response for the COVID-19 outbreak-Taiwan's experience. J. Formos. Med. Assoc. 2020, 119, 771. [CrossRef] [PubMed]

25. Prevention and Control of COVID-19 in Taiwan. Available online: https://www.cdc.gov.tw/En/Bulletin/Detail/UTn3UpemfvRtr3 r991m-Hw?typeid=158 (accessed on 30 May 2021).

26. Boutis, K.; Stephens, D.; Lam, K.; Ungar, W.J.; Schuh, S. The impact of SARS on a tertiary care pediatric emergency department. CMAJ 2004, 171, 1353-1358. [CrossRef] [PubMed] 
27. Yen, M.Y.; Schwartz, J.; Chen, S.Y.; King, C.C.; Yang, G.Y.; Hsueh, P.R. Interrupting COVID-19 transmission by implementing enhanced traffic control bundling: Implications for global prevention and control efforts. J. Microbiol. Immunol. Infect. 2020, 53, 377-380. [CrossRef] [PubMed]

28. Dubey, S.; Biswas, P.; Ghosh, R.; Chatterjee, S.; Dubey, M.J.; Chatterjee, S.; Lahiri, D.; Lavie, C.J. Psychosocial impact of COVID-19. Diabetes Metab. Syndr. 2020, 14, 779-788. [CrossRef] [PubMed]

29. Pfefferbaum, B.; North, C.S. Mental health and the Covid-19 pandemic. N. Engl. J. Med. 2020, 383, 510-512. [CrossRef] [PubMed]

30. Qiu, J.; Shen, B.; Zhao, M.; Wang, Z.; Xie, B.; Xu, Y. A nationwide survey of psychological distress among Chinese people in the COVID-19 epidemic: Implications and policy recommendations. Gen. Psychiatry 2020, 33, e100213. [CrossRef] [PubMed] 